\title{
Relationship between antibiotic resistance, biofilm formation, genes coding virulence factors and source of origin of Pseudomonas aeruginosa clinical strains
}

\author{
Magdalena Ratajczak ${ }^{1, A-B, D, F}{ }^{\text {, Dorota Kamińska }}{ }^{1, A, C-D, F} \oplus$, \\ Dorota Małgorzata Nowak-Malczewska ${ }^{1, C, F \oplus}$, Anna Schneider ${ }^{2, B, F} \oplus$, Jolanta Dlugaszewska, ${ }^{1, E-F} \oplus$ \\ ${ }^{1}$ Chair and Department of Genetics and Pharmaceutical Microbiology, Poznan University of Medical Sciences, Poland \\ ${ }^{2}$ Microbiology Clinical Laboratory, University Hospital of the Lord's Transfiguration, Poznań, Poland \\ A - Research concept and design, B - Collection and/or assembly of data, C - Data analysis and interpretation, \\ $D$ - Writing the article, E-Critical revision of the article, F- Final approval of article
}

Ratajczak M, Kamińska D, Nowak-Malczewska DM, Schneider A, Dlugaszewska J. Relationship between antibiotic resistance, biofilm formation, genes coding virulence factors and source of origin of Pseudomonas aeruginosa clinical strains. Ann Agric Environ Med. 2021; 28(2): 306-313. doi: $10.26444 /$ aaem/122682

\begin{abstract}
Introduction and objective. Pseudomonas aeruginosa is an opportunistic pathogen that causes difficult with treating infections, especially in the immunocompromised and patients with some underlying disease. The aim of the study is to assess the antibiotic resistance, biofilm formation, and the presence of genes encoding various virulence factors in clinical isolates of $P$. aeruginosa.

Materials and methods. Seventy-three clinical isolates of Pseudomonas aeruginosa were tested. Antimicrobial Susceptibility Testing (AST) and carbapenemases production was performed in accordance with the EUCAST guidelines. The ability to form biofilm was assessed by crystal violet assay. Genes encoding selected virulence factors were detected using standard polymerase chain reaction (PCR).

Results. Among the 73 clinical isolates of $P$. aeruginosa, $41.1 \%$ were resistant to imipenem, $61.6 \%$ to meropenem, $30.1 \%$ to ciprofloxacin and $15.1 \%$ to tobramycin. Over $20 \%$ of isolates were producers of MBL. Antibiotic resistance profiling revealed that $23.3 \%$ of strains were sensitive to all antibiotics, $60.3 \%$ were LDR phenotype, and $16.4 \%$ were MDR phenotype. The majority of strains (73.6\%) were strong-biofilm producers, $17.0 \%$ were moderate and $9.4 \%$ were weak biofilm producers. PCR analysis showed the presence of lasB, aprE and prpL genes in most of the tested strains $(93.1 \%, 87.7 \%$ and $74.0 \%$, respectively). Among strong biofilm producers, $22.2 \%$ were MDR, $63.0 \%$ of strains represented LDR phenotype, and $14.8 \%$ were sensitive to all antibiotics. Moderate and weak biofilm producers were LDR and sensitive phenotypes only (respectively, $58.3 \%$ and 42.9 - LDR, 41.7 and $51.7 \%$ - sensitive).

Conclusions. High frequency of MDR strains and their ability of biofilm formation and virulence factors may be a threat to effective therapy, and can increase morbidity and mortality of infected patients.
\end{abstract}

\section{Key words}

antimicrobial resistance, Pseudomonas aeruginosa, biofilm, virulence factors

\section{INTRODUCTION}

Pseudomonas aeruginosa is an opportunistic pathogen that can cause infections in immunocompromised individuals, most commonly in patients being treated in intensive care, surgery, and burn units. $P$. aeruginosa infections most frequently involve the respiratory tract, placenta, urinary system, skin, and soft tissues, where the greatest risk is associated with the infection of postoperative wounds, burns and pressure ulcers $[1,2]$. In the USA, $P$. aeruginosa is among the top six bacterial species responsible for nosocomial infections, and the second most common pathogen causing ventilator-associated pneumonia and catheter-related urinary tract infections [2]. Despite advences in critical-care management, $P$. aeruginosa infections are associated with a mortality rate reaching $20 \%-50 \%[3,4,5,6,7]$.

Address for correspondence: Magdalena Ratajczak, University of Medical Science, Poznań, Poland

E-mail:mratajczak@ump.edu.pl

Received: 20.02.2020; accepted: 11.05.2020; first published: 04.06.2020
Infections caused by $P$. aeruginosa pose therapeutic difficulties and frequently assume a chronic course. These are attributable to the fact that $P$. aeruginosa produces several virulence factors both - cell surface components (lipopolysaccharides, fimbriae, flagella, mucus, lectins) and extracellular product (exotoxin A; exoenzymes S, T, U, and Y; alkaline protease, type IV protease, elastase, neuraminidase, phospholipase, and the pigment pyocyanin). Toxins and enzymes inhibit the phagocytosis, damage macrophages, and inactivate the immunoglobulins $\operatorname{IgG}$ and $\operatorname{IgA}[8,9]$. Based on its ability to use different energy sources and adhere to various surfaces, $P$. aeruginosa is capable of surviving in nutrient-poor environments. The attachment of motile bacteria to a surface and their subsequent division lead to the formation of microcolonies. Bacterial microcolonies mature and coalesce to form biofilms [10]. Bacterial biofilm protects against the host's immune system and antimicrobial substances [11].

The production of biofilm and virulence factors is regulated by the Quorum Sensing $(Q S)$ system. QS is a process of bacterial 
communication that regulates gene expression depending on the density of bacterial cell populations. The phenomenon affects genes that are indispensable for bacterial function and growth, horizontal gene transfer, and virulence. The QS mechanism in $P$. aeruginosa plays a key role in the synthesis of virulence factors, including protease, pyocyanin, exotoxin A, alkaline protease, lectins, and rhamnosyltransferase [12, $13,14]$. The process of $Q S$ contributes to the development of chronic pulmonary infections in patients with cystic fibrosis, the spread of infection leading to sepsis, and the development of tissue pathologies [15].

The sensitivity of bacteria in planktonic and biofilm forms to antimicrobial agents is varied. Biofilm forming microorganisms are far more resistant to antibiotics than bacteria growing as individual cells [16]. The biofilm formed by $P$. aeruginosa is considered to be one of the major causes of therapeutic failure [17].

$P$. aeruginosa has both natural (intrinsic) and acquired resistance to a range of antibiotic classes. Natural resistance applies to $\beta$-lactam antibiotics (benzylpenicillin, isoxazolyl penicillins, aminopenicillin and their combinations with $\beta$-lactamase inhibitors, first- and second-generation cephalosporins), tetracyclines, tigecycline, chloramphenicol and trimethoprim [3]. Acquired resistance is associated primarily with the production of enzymes that break down $\beta$-lactam antibiotics. A significant role in the antibiotic resistance of $P$. aeruginosa is attributed to metallo- $\beta$ lactamases (MBLs) production. MBLs are characterized by an extremely broad substrate spectrum, including all penicillins, cephalosporins, and carbapenems. Crucially, these enzymes exhibit a complete lack of susceptibility to all available clinically used $\beta$-lactamase inhibitors. An aspect of paramount importance is the ability of MBLs to inactivate carbapenems effectively, often referred to as 'antibiotics of last resort' in the treatment of infections caused by multiresistant Gram-negative bacterial strains [18, 19].

\section{OBJECTIVE}

The aims of the study were to evaluate antimicrobial resistance, biofilm formation and characterization of the genes encoding selected virulence factors of Pseudomonas aeruginosa clinical strains.

\section{MATERIALS AND METHOD}

Bacterial strains. Seventy-three strains of $P$. aeruginosa isolated from patients diagnosed with different clinical infection were evaluated. The strains were isolated in the Microbiology Clinical Laboratory at the University Hospital of Lord's Transfiguration in Poznań, Poland, in the period January - November 2018. The sources of isolation of the tested clinical strains are presented in Table 2.

The identification of the genus level was carried out based on cellular morphology and the Gram staining, macroscopic assessment of bacterial colonies, and conventional biochemical tests. Identification to the level of species was performed by VITEK $^{\oplus}$ Compact automated identification system using GN Cards - test for the identification of Enterobacteriaceae and a selected group of glucose nonfermenting Gram-negative organisms.
Antimicrobial susceptibility testing. The testing was performed by the disc diffusion method in accordance with the EUCAST [20] recommendations. Ciprofloxacin $5 \mu \mathrm{g}$, ceftazidime $10 \mu \mathrm{g}$, piperacillin $30 \mu \mathrm{g}$, tobramycin $10 \mu \mathrm{g}$, imipenem $10 \mu \mathrm{g}$, and meropenem $10 \mu \mathrm{g}$ were used to test the drug susceptibilityto Pseudomonas spp. P. aeruginosa ATCC 27853 was used as a reference strain. Carbapenemases production was screened using the Carba NP test and phenotypic double disc synergy tests with EDTA (MBL) and boronic acid (KPC).

The following resistance phenotypeswere distinguished: sensitive (sensitivity to all antibiotics tested), low-level resistant (LDR; resistance to $<3$ antimicrobial categories;) and multidrug resistant (MDR; resistance to $\geq 3$ categories).

Quantitative assessment of biofilm formation in vitro. To evaluate biofilm formation, the crystal violet assay was used. Each well of a sterile 96-well flat-bottom plastic plate was filled with $200 \mu \mathrm{L}$ of standardized bacterial suspension (density c.a. $10^{6} \mathrm{CFU} / \mathrm{mL}$ ). Negative control wells contained broth only. Pseudomonas aeruginosa PAO1 was used as a positive control. The plates were closed and incubated aerobically for $24 \mathrm{~h}$ at $37^{\circ} \mathrm{C}$. Then, the content of each well was aspirated, and each well washed three times with $250 \mu \mathrm{L}$ of sterile physiological saline. The plates were shaken in order to remove all non-adherent bacteria. After the washing steps, biofilms were stained for $15 \mathrm{~min}$ with a $2 \%$ solution of crystal violet $(200 \mu \mathrm{L})$. Each well was then washed three times, once again with $250 \mu \mathrm{L}$ of sterile physiological saline After the plates were air-dried, $200 \mu \mathrm{L}$ of $99 \%$ methanol per well was added. The absorbance of each well was measured at $590 \mathrm{~nm}$ using an Infinite M200 plate reader (Tecan). The test was repeated three times for each strain.

The interpretation of biofilm production was according to the criteria described by [21]. The mean optical density (OD) of the negative control was considered the cut-off. All strains were classified based on the following criteria: non-adherent $(\mathrm{OD} \leq \mathrm{ODc})$, weakly adherent $(\mathrm{ODc}<\mathrm{OD} \leq$ $2 \times \mathrm{ODc})$, moderately adherent $(2 \times \mathrm{ODc}<\mathrm{OD} \leq 4 \times \mathrm{ODc})$, strongly adherent $(\mathrm{OD}>4 \times \mathrm{ODc})$.

Detection of genes taking part in Quorum Sensing and genes encoding virulence factors._DNA extraction was carried out using the thermal in-house method subjecting the bacteria cell wall to the process of lysis, by warming up $\left(60 \pm 2{ }^{\circ} \mathrm{C}\right)$ and cooling down $\left(-20 \pm 2{ }^{\circ} \mathrm{C}\right)$ during six cycles lasting 30 seconds each. Bacterial DNA was extracted using the thermal in-house method, subjecting the bacteria cell wall to the process of lysis, by warming up $\left(60 \pm 2^{\circ} \mathrm{C}\right)$ and cooling down $\left(-20 \pm 2{ }^{\circ} \mathrm{C}\right)$ during six cycles lasting 30 seconds each.

Genes encoding various $Q S$ systems (lasl, lasR, rhlI, $r h l R, a m b D, a m b E$, $p q s A, p q s B)$, and genes encoding tested virulence factors: elastase (lasB), alkaline protease (aprE), endopeptidase IV ( $p r p L$ ) were detected using single standard polymerase chain reaction (PCR). The specificity of the starters was checked in BLAST Assembled Ref Genomes (https://blast.ncbi.nlm.nih.gov/Blast.cgi program). The following PCR mixture was used: buffer with $\mathrm{MgCl}_{2}(1 \times)$, dNTP Mix $(0.2 \mathrm{mM}$ each), primer pair $(10 \mu \mathrm{M})$, thermostable Taq polymerase (1U), DNA (100-200 ng) isolated from the tested $P$. aeruginosa strains. As a negative control, the reaction mixture with water was used instead of bacterial 
DNA. The positive control was a DNA sample isolated from the strain of $P$. aeruginosa PAO1. Parameters of amplification cycles: denaturation in $94^{\circ} \mathrm{C}$ for 3 minutes, hybridization of starters, for 1 minute and extending starters in $72^{\circ} \mathrm{C}$ for 1 minute, for 30 cycles (Table 1 ).

The presence of the amplified products of PCR was evaluated using electrophoretic separation in $1.5 \%$ agarose gel against the marker's molecular weight. The electrophoresis was carried out within 40 minutes under constant voltage of $130 \mathrm{~V}$. The resulting bands were visualized by transilluminator in UV light (Syngen).

Table 1. PCR detection of tested genes. Oligonucleotide sequences for identification of genes taking part in Quorum Sensing and genes encoding virulence factors in $\mathrm{P}$. aeruginosa strains

\begin{tabular}{|c|c|c|c|}
\hline & Sequence $\left(5^{\prime}-3^{\prime}\right)$ & $\begin{array}{l}\text { Amplicon } \\
\text { size (bp) }\end{array}$ & $\begin{array}{l}\text { Annealing } \\
\text { temp. (0C) }\end{array}$ \\
\hline \multicolumn{4}{|c|}{ Quorum Sensing genes } \\
\hline lasl & $\begin{array}{l}\text { F:GGCTGGGACGTTAGTGTCAT } \\
\text { R: CCAGCGTACAGTCGGAAAA }\end{array}$ & 274 & 59.8 \\
\hline las $R$ & $\begin{array}{l}\text { F: AAGGACAGCCAGGACTACGA } \\
\text { R: CCGAGCAGTTGCAGATAACC }\end{array}$ & 490 & 54.6 \\
\hline rhll & $\begin{array}{l}\text { F: GTTCGACCATCCGCAAAC } \\
\text { R: GTCTCGCCCTTGACCTTCT }\end{array}$ & 354 & 60.9 \\
\hline$r h / R$ & $\begin{array}{l}\text { F: CATGGCACCTATCCCAAGG } \\
\text { R: GGTCCATTGCAGGATCTCG }\end{array}$ & 396 & 60.9 \\
\hline$p q s A$ & $\begin{array}{l}\text { F: CCTGTICCTGCAATACACCTC } \\
\text { R: CCATAGCCGAAGAACATCTTG }\end{array}$ & 163 & 56,5 \\
\hline$p q s B$ & $\begin{array}{l}\text { F: GTCTTCGACCTCACCGACT } \\
\text { R: GCTGTCCACTTCCAATCCCT }\end{array}$ & 129 & 56,0 \\
\hline$a m b E$ & $\begin{array}{l}\text { F: ATGCGGCCTACATGATCTTC } \\
\text { R: CGGAGAGCAACTGGAGAATC }\end{array}$ & 201 & 65,5 \\
\hline$a m b D$ & $\begin{array}{l}\text { F: GTGTTCACCTCCACCGAGTT } \\
\text { R: CGGTGTCTGGCAGTAGAAGTG }\end{array}$ & 263 & 62,0 \\
\hline \multicolumn{4}{|c|}{ Virulence factors genes } \\
\hline $\begin{array}{l}\text { Alkaline protesae } \\
(\text { aprE })\end{array}$ & $\begin{array}{l}\text { F: GCAGAACAAGCACCCTACTAC } \\
\text { R: AACAGGGGCTTGAACAGGTA }\end{array}$ & 156 & 60.40 \\
\hline $\begin{array}{l}\text { Elastase } \\
\text { (lasB) }\end{array}$ & $\begin{array}{l}\text { F: CGAGAATGACAAAGTGGAACTG } \\
\text { R: CGTAGGTGTACTTGCCGATCTT }\end{array}$ & 218 & 60.0 \\
\hline $\begin{array}{l}\text { Endopeptidase IV } \\
(p r p L)\end{array}$ & $\begin{array}{l}\text { F: GTCACCTACGACGGGCATAC } \\
\text { R: CGCTGAAATCGGAGAAGTAGTC }\end{array}$ & 196 & 62.2 \\
\hline
\end{tabular}

Statistical analysis. R statistical package [22] was used for statistical analyses. The relationship between the prevalence of the source of isolation, antibiotic resistance phenotype, and biofilm production was determined using Pearson's Chi-square test. A $P$ values less than 0.05 was considered significant.

\section{RESULTS}

Antimicrobial susceptibility. The drug susceptibility profile is shown in Figure 1A. The current study demonstrated strains resistant to beta-lactam antibiotics, especially to carbapenems: imipenem (41.1\%) and meropenem (61.6\%). Among the tested strains, $30.1 \%$ were resistant to ciprofloxacin and $15.1 \%$ to tobramycin. $23.3 \%$ of the strains were producers of Metallo- $\beta$-lactamases. None of the strains produced Klebsiella pneumoniae carbapenemase (KPC). Sensitivity to all antibiotics was found in $23.3 \%$ of strains, $60.3 \%$ of strains showed a phenotype LDR, and $16.4 \%$ were MDR phenotype

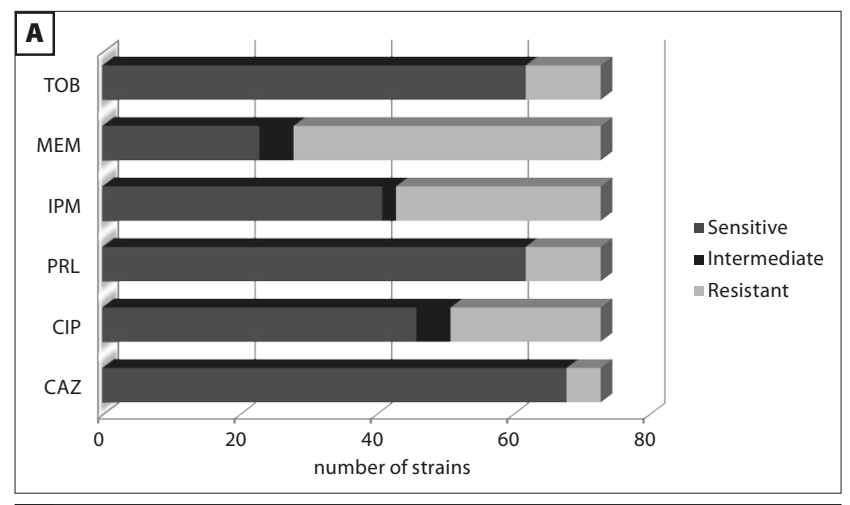

B

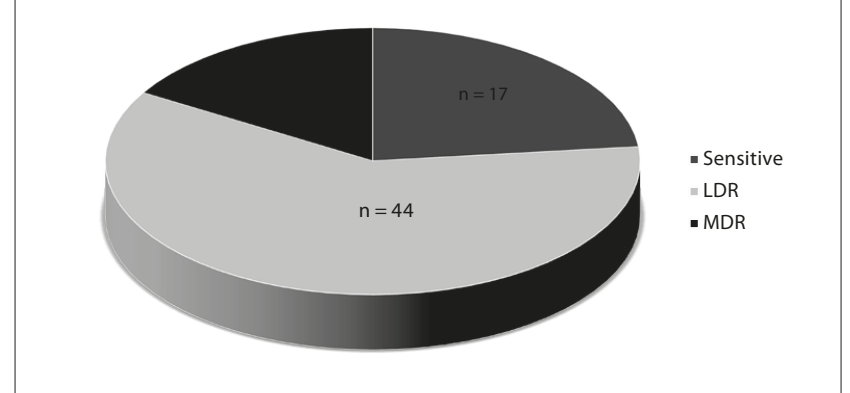

Figure 1. Antibiotics susceptibility.

A - Antimicrobial susceptibility profile: CAZ - ceftazidime; CIP - ciprofloxacin; PRL piperacillin; IPM - imipenem; MEM - meropenem; TOB - tobramycin.

$B$ - Antimicrobial resistance phenotypes: Sensitive (sensitivity to all antibiotics tested) - LDR (low-level resistant; resistance to $<3$ antimicrobial categories) and MDR (multidrug resistant; resistance to $\geq 3$ categories).

(Figure 1B). All MDR strains were carbapenem (meropenem and imipenem) resistant.

The ability of biofilm formation. The ability to biofilm formation of 73 strains of $P$. aeruginosa was tested using the spectrophotometric method with crystal violet. Based on the absorbance value, following the biofilm formation criteria, all bacteria strains were qualified into appropriate groups in terms of the biofilm-forming rate. The majority (73.6\%) of $P$. aeruginosa strains were found to be strong biofilm producers. Only $9.6 \%$ of strains showed a weak biofilm-forming ability (Tab. 2).

Prevalence of genes encoding virulence factor and Quorum Sensing. Qualitative analysis showed that the lasB gene was present in $93.1 \%$, aprE in $87.7 \%$, and prpL in $74.0 \%$ of the tested strains (Tab. 2). Analyzing the results, it was noted that $67.1 \%$ of the strains studied had all the genes responsible for the production of virulence factors. Only 2 strains of $P$. aeruginosa did not have any of the identified genes. These strains belonged to strong biofilm producers. Four strains did not have 2 of the analyzed genes simultaneously. Three of these strains had the ability to form a strong biofilm, and one to a weak degree (Tab. 2). Qualitative identification of genes involved in the QS system showed that 42 strains had all the genes participating in the QS (Tab. 2).

Correlation of results. As a correlation of the obtained results, the examined strains were analyzed for the source of isolation and their ability to create biofilm. Out of 53 strains of $P$. aeruginosa isolated from the lower respiratory tract, $73.6 \%$ exhibited a strong biofilm-forming ability, while $17.0 \%$ 
Table 2. Qualitative identification of genes taking part in e Quorum Sensing (QS) and genes encoding virulence factors, biofilm formation rate, and phenotype resistance in Pseudomonas aeruginosa strains isolated from different clinical infection

\begin{tabular}{|c|c|c|c|c|c|c|c|c|c|c|c|c|c|c|}
\hline \multirow{2}{*}{\multicolumn{2}{|c|}{ Specimens }} & \multirow{3}{*}{$\frac{\text { Biofilm }}{\mathrm{s}}$} & \multicolumn{8}{|c|}{ QS genes } & \multicolumn{3}{|c|}{ Virulence genes } & \multirow{3}{*}{$\begin{array}{c}\text { Resistance } \\
\text { phentype }\end{array}$} \\
\hline & & & \multirow{2}{*}{$\frac{\text { lasl }}{+}$} & \multirow{2}{*}{$\begin{array}{c}\text { lasR } \\
-\end{array}$} & \multirow{2}{*}{$\frac{r h l l}{+}$} & \multirow{2}{*}{$\frac{r h / R}{-}$} & \multirow{2}{*}{$\frac{a m b D}{-}$} & \multirow{2}{*}{$\begin{array}{c}a m b E \\
+\end{array}$} & \multirow{2}{*}{$\begin{array}{c}\text { pqsA } \\
+\end{array}$} & \multirow{2}{*}{$\begin{array}{c}p q s B \\
+\end{array}$} & \multirow{2}{*}{$\begin{array}{c}\text { las } B \\
+\end{array}$} & \multirow{2}{*}{$\frac{\text { aprE }}{+}$} & \multirow{2}{*}{$\begin{array}{c}\text { prpL } \\
+\end{array}$} & \\
\hline 1 & resp. tract & & & & & & & & & & & & & \\
\hline 2 & resp. tract* & $S$ & + & + & + & + & - & + & + & - & + & + & + & LDR \\
\hline 3 & wound & $S$ & + & + & + & + & + & + & + & + & + & + & + & Sensitive \\
\hline 4 & resp. tract* & $S$ & + & - & + & - & + & + & + & + & + & + & - & MDR \\
\hline 6 & wound & M & + & + & + & + & + & + & + & + & + & + & + & LDR \\
\hline 7 & resp. tract & $S$ & + & + & + & + & + & + & + & + & + & - & + & Sensitive \\
\hline 8 & blood & M & + & + & + & + & + & + & + & + & + & + & + & Sensitive \\
\hline 9 & resp. tract* & M & + & + & + & + & + & + & + & + & + & + & - & Sensitive \\
\hline 10 & resp. tract & $M$ & + & + & + & + & + & + & + & + & + & + & + & LDR \\
\hline 12 & resp. tract* & $M$ & + & + & + & + & + & + & + & + & + & + & + & LDR \\
\hline 14 & resp. tract* & $\mathrm{S}$ & - & - & - & - & - & + & + & - & + & + & - & Sensitive \\
\hline 15 & resp. tract* & $\mathrm{S}$ & + & + & + & + & - & + & + & + & + & + & + & MDR \\
\hline 16 & blood & $\mathrm{S}$ & + & + & + & + & + & + & + & + & + & + & + & Sensitive \\
\hline 17 & urine & $\mathrm{S}$ & + & + & + & + & + & + & + & + & + & + & + & MDR \\
\hline 18 & resp. tract* & $M$ & + & + & + & + & + & + & + & + & + & + & + & Sensitive \\
\hline 19 & resp. tract* & W & + & + & + & + & + & + & + & + & + & + & + & Sensitive \\
\hline 20 & resp. tract* & $\mathrm{S}$ & + & + & + & - & + & + & + & - & + & + & + & MDR \\
\hline 21 & resp. tract* & $\mathrm{S}$ & + & + & + & + & + & + & + & + & + & + & + & MDR \\
\hline 23 & resp. tract & W & + & + & + & + & + & - & + & - & + & + & + & Sensitive \\
\hline 24 & resp. tract* & $M$ & + & + & + & + & + & + & + & + & + & + & + & Sensitive \\
\hline 25 & resp. tract & w & + & + & + & + & + & + & + & + & + & - & - & LDR \\
\hline 29 & resp. tract* & $\mathrm{S}$ & + & + & + & + & + & + & + & + & + & + & - & LDR \\
\hline 30 & wound & $\mathrm{S}$ & + & + & + & + & + & + & + & + & + & + & + & Sensitive \\
\hline 31 & resp. tract* & W & + & + & + & + & + & + & + & + & + & + & - & Sensitive \\
\hline 32 & resp. tract* & M & + & + & + & + & + & + & + & + & + & + & + & LDR \\
\hline 33 & urine & $\mathrm{S}$ & - & - & - & - & + & + & + & + & + & + & + & MDR \\
\hline 34 & urine & $\mathrm{S}$ & - & + & - & + & + & + & + & + & + & + & + & LDR \\
\hline 35 & wound & $M$ & + & - & - & + & + & + & + & + & + & + & + & Sensitive \\
\hline 36 & resp. tract & $\mathrm{s}$ & + & - & + & + & + & + & + & + & + & + & + & LDR \\
\hline 37 & blood & $\mathrm{S}$ & + & - & + & + & - & + & + & + & + & + & + & Sensitive \\
\hline 38 & urine & $\mathrm{S}$ & + & + & + & + & + & + & + & + & + & + & - & MDR \\
\hline 39 & resp. tract* & $\mathrm{S}$ & + & + & - & + & + & + & + & + & + & + & + & MDR \\
\hline 40 & urine & $\mathrm{S}$ & + & + & + & + & + & + & + & + & + & + & - & LDR \\
\hline 41 & resp. tract* & $\mathrm{S}$ & + & + & + & + & + & + & + & + & + & + & + & LDR \\
\hline 42 & wound & $\mathrm{S}$ & + & + & + & + & + & + & + & + & + & + & - & LDR \\
\hline 43 & resp. tract* & $\mathrm{S}$ & + & + & + & + & + & + & + & + & + & + & + & MDR \\
\hline 44 & urine & $\mathrm{S}$ & + & + & + & + & + & + & + & + & + & + & + & LDR \\
\hline 45 & wound & $\mathrm{S}$ & + & + & + & + & + & + & + & + & + & + & + & LDR \\
\hline 46 & wound & $\mathrm{S}$ & + & + & - & + & + & + & + & + & + & + & + & LDR \\
\hline 48 & resp. tract* & w & + & + & - & + & + & + & + & + & + & + & + & LDR \\
\hline 49 & wound & $\mathrm{S}$ & + & + & - & + & + & - & + & + & + & + & - & LDR \\
\hline 50 & resp. tract & $\mathrm{S}$ & + & + & + & + & + & + & + & + & + & + & + & LDR \\
\hline 51 & resp. tract* & $\mathrm{S}$ & + & + & + & + & + & + & + & + & + & + & + & LDR \\
\hline 52 & resp. tract & $\mathrm{S}$ & + & + & + & + & + & + & + & + & + & + & + & LDR \\
\hline
\end{tabular}


Table 2. Qualitative identification of genes taking part in e Quorum Sensing (QS) and genes encoding virulence factors, biofilm formation rate, and phenotype resistance in Pseudomonas aeruginosa strains isolated from different clinical infection (continuation)

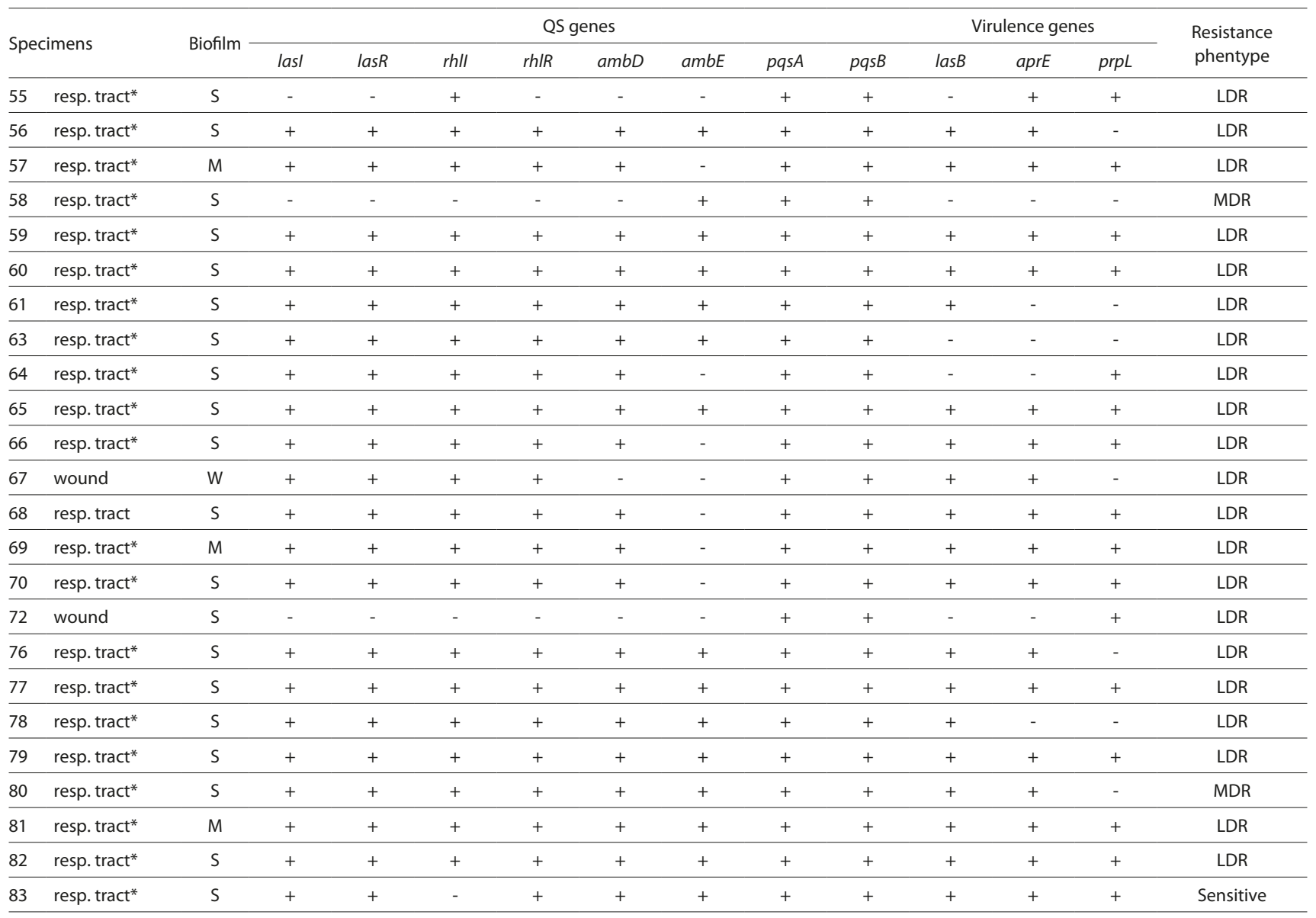

* patients with cystic fibrosis.

S-strong; M - moderate; W - weak; CAZ - ceftazidime; CIP - ciprofloxacin; PRL - piperacillin; IPM - imipenem; MEM - meropenem; TOB - tobramicin; MBL - metallo- $\beta$-lactamases; KPC - Klebsiella pneumoniae carbapenemase: Sensitive (sensitivity to all antibiotics tested); MDR-multidrug-resistant (non-susceptible to $\geq 3$ categories); LDR - low-level resistant ( 33 antimicrobial categories).

were moderate and $9.4 \%$ weak biofilm producers. Similarly, bacterial strains isolated from wounds were dominated by strong biofilm producers (63.6\%), followed by strains with a moderate $(18.2 \%)$ and weak (18.2\%) biofilm-forming capacity. All the strains of $P$. aeruginosa isolated from urine (6 in total) exhibited a strong biofilm-forming ability. Two strains isolated from blood showed a strong biofilm-forming ability, and one exhibited weak biofilm forming potential. The observed differences were not found to be statistically significant $(\mathrm{p}=0.6331)$ (Tab. 3$)$.

Analysis of the prevalence of different resistance phenotypes among the strains with varying biofilm-forming ability revealed that all strains with the resistance phenotype MDR belonged to the group of strong biofilm producers. They accounted for $22.2 \%$ of strains with strong biofilmforming capacity. Furthermore, strains with the resistance phenotype LDR represented $63.0 \%$, and strains showing sensitivity to all antibiotics $-14.8 \%$. Regarding the group of moderate biofilm producers, $58.3 \%$ of strains represented the resistance phenotype LDR, while $41.7 \%$ were sensitive to all antibiotics studied. Among the weak biofilm producers, $42.9 \%$ of strains had the LDR phenotype, while $57.1 \%$ of strains were susceptible to all antibiotics. The results were found to be statistically significant $(\mathrm{p}=0.02151)$ (Tab. 3). No statistical relationship was confirmed for the remaining features (Tab. 3).

\section{DISCUSSION}

Antibiotics dedicated to fighting infections caused by $P$. aeruginosa lose their therapeutic efficacy because of the growth of multi-drug resistance in $P$. aeruginosa strains $[2,23,24,25]$. The presented study found a high degree of resistance to carbapenem antibiotics. $41.0 \%$ of the studied strains were resistant to imipenem, and $61.6 \%$ to meropenem. Other authors have also reported high levels of resistance to carbapenems.

According to studies conducted by the International Nosocomial Infection Control Consortium (INICC) in a total of 36 countries (Latin America, Asia, Africa, and Europe), $47.2 \%$ of $P$. aeruginosa strains isolated from infections were imipenem resistant [24]. Studies conducted on strains isolated from patients hospitalized with pneumonia in the United States and Europe showed that 23.7\% and 34.2\% of the evaluated strains were resistant to meropenem, respectively. In Brazil, the Surveillance and Control of Pathogens of Epidemiological Importance found that $35.8 \%, 36.8 \%, 36.6 \%$ of $P$. aeruginosa strains were resistant to meropenem, imipenem, and ceftazidime, respectively [26]. Studies conducted in Poland on P. aeruginosa isolates obtained from patients with cystic fibrosis showed $72.2 \%$ of mucoid strains, and $56.2 \%$ of non-mucoid strains were meropenem resistant [27]. 
Table 3. Numbers of Pseudomonas aeruginosa strains according to analyzed features. Pearson's Chi-square test was performed to determine the dependence between variables

\begin{tabular}{lcccc}
\hline A) Biofilm formation and drug resistance phenotype \\
\hline Biofilm/Resistance phenotype & MDR & LDR & Sensitive \\
\hline S & 12 & 34 & 8 \\
\hline M & 0 & 7 & 5 \\
\hline W & 0 & 3 & 4 \\
\hline p-value & \multicolumn{3}{|c}{0.02151}
\end{tabular}

\section{B) Source of samples and biofilm formation}

\begin{tabular}{lccc}
\hline Source/Biofim & S & M & W \\
\hline blood & 2 & 1 & 0 \\
\hline resp. tract & 6 & 1 & 2 \\
\hline resp. tract* & 33 & 8 & 3 \\
\hline urine & 6 & 0 & 0 \\
\hline wound & 7 & 2 & 2 \\
\hline p-value & & 0.6331
\end{tabular}

C) No. of virulence genes and drug resistance phenotype

\begin{tabular}{lccc}
\hline No. of virulence genes/Resistance phenotype & MDR & LDR & Sensitive \\
\hline 0 & 1 & 1 & 0 \\
\hline 1 & 0 & 5 & 0 \\
\hline 2 & 3 & 8 & 6 \\
\hline 3 & 8 & 30 & 11 \\
\hline p-value & & 0.3447 &
\end{tabular}

D) No. of QS genes and drug resistance phenotype

\begin{tabular}{lccc}
\hline No. of QS genes/Resistance phenotype & MDR & LDR & Sensitive \\
\hline 0 & 0 & 0 & 0 \\
\hline 1 & 0 & 0 & 0 \\
\hline 2 & 0 & 1 & 0 \\
\hline 3 & 1 & 1 & 0 \\
\hline 4 & 1 & 0 & 0 \\
\hline 5 & 0 & 5 & 0 \\
\hline 6 & 2 & 4 & 3 \\
\hline 7 & 3 & 10 & 3 \\
\hline 8 & 5 & 27 & 10 \\
\hline p-value & & 0.5821 &
\end{tabular}

E) No. of virulence genes and biofilm formation

\begin{tabular}{lccc}
\hline No. of virulence genes/Biofilm & S & M & W \\
\hline 0 & 2 & 0 & 0 \\
\hline 1 & 4 & 0 & 1 \\
\hline 2 & 13 & 1 & 3 \\
\hline 3 & 35 & 11 & 3 \\
\hline -value & 0.4047 & &
\end{tabular}

F) No. of QS genes and biofilm formation

\begin{tabular}{lccc}
\hline No. of QS genes/Biofilm & S & M & W \\
\hline 0 & 0 & 0 & 0 \\
\hline 1 & 0 & 0 & 0 \\
\hline 2 & 2 & 0 & 0 \\
\hline 3 & 2 & 0 & 0 \\
\hline 4 & 1 & 0 & 0 \\
\hline 5 & 1 & 0 & 0 \\
\hline 6 & 6 & 1 & 2 \\
\hline 7 & 12 & 2 & 2 \\
\hline 8 & 30 & 9 & 3 \\
\hline$p$-value & & 0.956 &
\end{tabular}

p-value

0.956

* patients with cystic fibrosis.

S - strong, M - moderate, W - weak, Sensitive (sensitivity to all antibiotics tested), MDR - multidrug-resistant (non-susceptible to $\geq 3$ categories), LDR - low-level resistant $<3$ antimicrobial categories)
The prevalence of carbapenem resistance among Gramnegative bacilli is increasing worldwide. The acquisition of MBL-encoding genes is considered to be the most important mechanism underlying carbapenem resistance [28]. Among the strains evaluated in the present study, 23.3\% had the capacity to produce these enzymes. Brazilian researchers showed that $73.53 \%$ of $P$. aeruginosa strains isolated from a variety of infections were MBL-positive [29]. On account of the coexistence of MBL-encoding genes with other resistance genes, MBL-producing strains usually have a complex MDR phenotype. The occurrence of MBL-producing $P$. aeruginosa strains in a hospital setting has been reported and confirmed worldwide by several authors [25, 30, 31].

Both multiple resistance to antibiotics and biofilm formation may lead to difficulties in the treatment of infections where $P$. aeruginosa is the etiological factor. The present study showed that all $P$. aeruginosa strains isolated from clinical specimens were capable of biofilm formation under in vitro conditions. However, they differed in the degree of biofilm formation. Most strains showed a strong biofilm-forming capacity (74.0\%), while significantly fewer strains exhibited moderate (16.4\%) and weak (9.6\%) biofilmforming potential. Similar findings were reported by other authors [32, 33, 34]. Studies conducted in 2018 by J. Lima et al. [33] to assess the biofilm-forming ability showed that $77.5 \%$ of clinical strains of $P$. aeruginosa were capable of producing biofilm. Da Silva Carvalho et al. [34] found that $86.5 \%$ of $P$. aeruginosa strains studied were classified as strong or moderate biofilm producers.

P. aeruginosa has 4 QS systems (las, rhl, pqs, and iqs), which are interconnected and organized in a hierarchical manner [35]. Because the systems are interlinked, the absence of any one component does not affect the QS expression ability of cells [9]. Some QS-deficient clinical strains were found to be capable of causing infection in humans [14]. The design of this study involved the identification of QS genes as well as virulence-determining genes, the expression of which is regulated by the $Q S$ system.

The present study shows that $57.5 \%$ of the strains had all the studied genes linked to the QS system. Karatuna and Yagci [36] observed similar results. Their studies of $P$. aeruginosa strains isolated from respiratory tract infections showed that $68.7 \%$ of isolates had all 4 genes, while $18.7 \%$ of strains did not have any of the studied genes. In their analysis of $P$. aeruginosa strains isolated from different clinical specimens, Kadhim and Ali [37] found that $81.6 \%$ of the isolates had at least one of the studied genes. The results obtained by PerezIberreche [38] for strains isolated from respiratory infections also show that $90.1 \%$ of the strains had all the genes studied. Only one isolate derived from cystic fibrosis patients, and one from non-cystic fibrosis patients did not have any of the analyzed genes involved in the QS [39]. Different findings were reported by Sabharwal et al. [9] for strains isolated from urinary tract infections. Of the strains studied, only $33.3 \%$ of the isolates had all the genes under analysis.

A qualitative analysis of genes conditioning the production of virulence factors in $P$. aeruginosa cells showed that the gene for elastase was present in the majority of strains studied (93.1\%). Comparable results were obtained by Senturk S. et al. [14] investigating strains isolated from urinary tract infections. The gene responsible for the synthesis of elastase was identified in $86.59 \%$ of all $P$. aeruginosa strains [12]. A slightly lower percentage (75\%) of isolates possessing the 
gene encoding elastase synthesis was reported by Sabharwal et al. [9] in their analysis of strains originating from urinary tract infections.

The gene determining the production of alkaline protease was present in $87.7 \%$ of $P$. aeruginosa isolates evaluated in the current study. Similar results were reported by Mittal R. et al. [39], who identified the alkaline protease gene in $50 \%$ of strains isolated from urinary tract infections. The strains showed the capacity to colonize kidney tissues [40]. In contrast, a study conducted by Sabharwal et al. [9] on $P$. aeruginosa strains isolated from urinary tract infections, showed the presence of alkaline protease in just $16.6 \%$ of the strains. The authors hypothesized that alkaline protease might not play an important role in the pathogenesis of urinary tract infections. The lowest proportion of bacterial strains analyzed in the study (74.0\%) had the gene encoding the production of endopeptidase IV. Similar results were obtained by researchers determining the presence of the gene in strains isolated from lower leg ulcers. The percentage of isolates having the gene was found to be $61.5 \%$. Kadhim and Ali [37] recorded slightly different results. They showed that $46.6 \%$ of $P$. aeruginosa strains isolated from various clinical infections had the gene responsible for endopeptidase IV production.

\section{CONCLUSIONS}

Based on the correlation of study findings, it was observed that the biofilm-forming ability was significantly higher among strains with the resistance phenotype MDR. It was also found that among the MBL-producing strains, there was only one weak biofilm producer, while the remaining strains exhibited a strong biofilm-forming ability. Similar findings have been reported by other authors $[40,16]$ who observed a correlation between the MDR phenotype and the ability of $P$. aeruginosa strains to form a biofilm.

Resistance to antimicrobial agents and the ability to grow as a biofilm are the main problems in the treatment of infections triggered by $P$. aeruginosa. The high degree of this resistance, and growth in the biofilm form, as well as the presence of various virulence factors, are the reasons for difficulties in managing infections caused by $P$. aeruginosa. The ability of $P$. aeruginos a to grow as a biofilm is believed to explain the weak relationship between antibiotic sensitivity under in vitro conditions and clinical response. A better understanding of the genes and mechanisms involved in biofilm formation by $P$. aeruginosa strains, as well as gaining insights into its structure, can assist in the development of new therapies to eliminate biofilm formation.

\section{REFERENCES}

1. Pachori P, Gothalwal R, Gandhi P. Emergence of antibiotic resistance Pseudomonas aeruginosa in intensive care unit; a critical review. Genes Dis. 2019; 6: 109-19.

2. Tümmler B. Emerging therapies against infections with Pseudomonas aeruginosa. F1000Res. 2019. https://doi.org/10.12688/ f1000research.19509.1

3. Urbanowicz P, Gniadkowski M. „Ciężkozbrojny” Pseudomonas aeruginosa: mechanizmy lekooporności i ich tło genetyczne. Kosmos. 2017; 66: 11-29.

4. Yoon E-J, Kim D, Lee H, Lee HS, Shin JH, Park YS, Kim YA, Shin JH, Shin KS, Uh Y, Jeong SH. Mortality dynamics of Pseudomonas aeruginosa bloodstream infections and the influence of defective OprD on mortality: prospective observational study. J Antimicrobial Chemotherapy. 2019; 74: 2774-2783.

5. Bosaeed M, Ahmad A, Alali A, Mahmoud E, Alswidan L, Alsaedy A, Alalwan B, Alshamrani M, Alothman M. Experience With CeftolozaneTazobactam for the Treatment of Serious Pseudomonas aeruginosa Infections in Saudi Tertiary Care Center. Infect Dis: Res Treatment. 2020; https://doi.org/10.1177/1178633720905977

6. Hattemer A, Hauser A, Diaz M, Scheetz M, Shah N, Allen JP, Porhomayon J, El-Solh AA. Bacterial and Clinical Characteristics of Health Care- and Community-Acquired Bloodstream Infections Due to Pseudomonas aeruginosa. Antimicrobial Agents and Chemotherapy. 2013; 57: 3969-3975.

7. Kim YJ, Jun YH, Kim YR, Park KG, Park YJ, Kang JY, Kim SI. Risk factors for mortality in patients with Pseudomonas aeruginosa bacteremia; retrospective study of impact of combination antimicrobial therapy. BMC Infect Dis. 2014; 14-161. doi:10.1186/1471-2334-14-161

8. Alhazmi A. Pseudomonas aeruginosa - pathogenesis and pathogenic mechanisms. Int J Biol. 2015; 7: 44-67.

9. Sabharwal N, Dhall S, Chhibber S, Harjai K. Molecular detection of virulence genes as markers in Pseudomonas aeruginosa isolated from urinary tract infections. Int Mol Epidemiol Genet. 2014; 5: 125-134.

10. Ghanbari A, Dehghany J, Schwebs T, Müsken M, Häussler S, MeyerHermann M. Inoculation density and nutrient level determine the formation of mushroom-shaped structures in Pseudomonas aeruginosa biofilms. Sci Rep. 2016; 9(6): 32097. doi: 10.1038/srep32097

11. Mulcahy LR, Isabella VM, Lewis K. Pseudomonas aeruginosa biofilms in disease. Microb Ecol. 2014; 68: 1-12. doi:10.1007/s00248013-0297-X

12. Wang Y, Gao L, Rao X, et al. Characterization of lasR-deficient clinical isolates of Pseudomonas aeruginosa. Sci Rep. 2018; 8: 13344. doi: 10.1038/s41598-018-30813-y

13. Hendiani S, Pornour M, Kashef N. Quorum-sensing-regulated virulence factors in Pseudomonas aeruginosa are affected by sublethal photodynamic inactivation. Pathodiagnosis and Photodynamic Terapy. 2019; 26: 8-12.

14. Senturk S, Ulusoy S, Bosgelmez-Tinaz G, Yagci A. Quorum sensing and virulence of Pseudomonas aeruginosa during urinary tract infections. J Infect Dev Ctries. 2012; 6: 501-507.

15. Vandeplassche E, Sass A, Lemarcq A, Dandekar AA, Coenye T, Crabbé A. In vitro evolution of Pseudomonas aeruginosa AA2 biofilms in the presence of cystic fibrosis lung microbiome members. Sci Rep. 2019; 9: 12859. doi: 10.1038/s41598-019-49371-y

16. Yekani M, Memar MY, Alizadeh N, Safaei N, Ghotaslou R. Antibiotic Resistance Patterns of Biofilm-Forming Pseudomonas Aeruginosa Isolates from Mechanically Ventilated Patients. Int J Sci Study. 2017; 5: $84-88$.

17. Kamali E, Jamali A, Ardebili A, Ezadi F, Mohebb A. Evaluation of antimicrobial resistance, biofilm forming potential, and the presence of biofilm-related genes among clinical isolates of Pseudomonas aeruginosa. BMC Res Notes. 2020; 13: 27. https://doi.org/10.1186/ s13104-020-4890-z

18. Stefani S, Campana S, Cariani L, Carnovale V, Colombo C, Lleo MM, Iula VD, Minicucci L, Morelli P, Pizzamiglio G, Taccetti G. Relevance of multidrug-resistant Pseudomonas aeruginosa infections in cystic fibrosis. Int J Med Microbiol. 2017; 307: 353-362.

19. Potron A, Poirel L, Nordmann P. Emerging broad-spectrum resistance in Pseudomonas aeruginosa and Acinetobacter baumannii: Mechanisms and epidemiology. Int J Antimicrob Agents. 2015; 45: 568-85.

20. EUCAST, 2017. EUCAST guideline for the detection of resistance mechanisms and specific resistances of clinical and/or epidemiological importance. Version 9.0. http://www.eucast.org/fileadmin/src/media/ PDFs/EUCAST files/Breakpoint tables/v9.0Breakpoint Tables.pdf

21. Stepanovic S, Vukovic D, Hola V, Di Bonaventura G, Djukić S, Cirković I, Ruzicka F. Quantification of biofilm in microtiter plates: overview of testing conditions and practical recommendations for assessment of biofilm production by staphylococci, APMIS. 2007; 115: 891-899.

22. https://cran.r-project.org/ (09.12.2019)

23. Cassini A, Högberg LD, Plachouras D, Quattrocchi A, Hoxha A, Simonsen GS, Colomb-Cotinat M, Kretzschmar ME, Devleesschauwer B, Cecchini M, Ouakrim DA, Oliveira TC, Struelens MJ, Suetens C, Monnet DL; Burden of AMR Collaborative Group. Attributable deaths and disability-adjusted life-years caused by infections with antibioticresistant bacteria in the EU and the European Economic Area in 2015: a population-level modelling analysis. Lancet Infect Dis. 2019; 19: 56-66.

24. Rosenthal VD, Rodrigues C, Álvarez-Moreno C, Madani N, Mitrev Z, Ye G, Salomao R, Ulger F, Guanche-Garcell H, Kanj SS, Cuéllar 
LE, Higuera F, Mapp T, Fernández-Hidalgo R, INICC members. Effectiveness of a multidimensional approach for prevention of ventilator-associated pneumonia in adult intensive care units from 14 developing countries of four continents: findings of the International Nosocomial Infection Control Consortium. Crit Care Med. 2012; 40: $3121-8$.

25. Hong DJ, Bae K, Jang I-H, Jeong SH, Kang H-K, Lee K. Epidemiology and Characteristics of Metallo- $\beta$-Lactamase-Producing Pseudomonas aeruginosa. Infect Chemother. 2015; 47: 81-97.

26. Marra AR, Pereira CA, Gales AC, Menezes LC, Cal RG, de Souza JM, Edmond MB, Faro C, Wey SB. Bloodstream infections with metallobeta-lactamase-producing Pseudomonas aeruginosa: epidemiology, microbiology, and clinical outcomes. Antimicrob Agents Chemother. 2006; 50: 388-90.

27. Iwańska A, Nowak J, Skorupa W, Augustynowicz-Kopeć E. Analysis of the frequency of isolation and drug resistance of microorganisms isolated from the airways of adult CF patients treated in the Institute of Tuberculosis and Lung Disease during 2008-2011. Pneumonol Alergol Pol. 2013; 81: 105-13.

28. Cornaglia G, Giamarellou H, Rossolini GM. Metallo- $\beta$-lactamases: a last frontier for $\beta$-lactams? Lancet Infect Dis. 2011; 11: 381-93.

29. Silva LV, Galdino AC, Nunes AP, dos Santos KR, Moreira BM, Cacci LC, Sodré CL, Ziccardi M, Branquinha MH, Santos AL. Virulence attributes in Brazilian clinical isolates of Pseudomonas aeruginosa. Int J Med Microbiol. 2014, 304: 990-1000.

30. Jovcic B, Lepsanovic Z, Suljagic V, Rackov G, Begovic J, Topisirovic L, Kojic M. Emergence of NDM-1 Metallo- $\beta$-Lactamase in Pseudomonas aeruginosa Clinical Isolates from Serbia. Antimicrobial Agents and Chemotherapy. 2011; 55: 3929-3931.

31. Pollini S, Mugnaioli C, Dolce D, Campana S, Neri AS, Taccetti G, Rossolini GM. Chronic infection sustained by a Pseudomonas aeruginosa High-Risk clone producing the VIM-1 metallo- $\beta$-lactamase in a cystic fibrosis patient after lung transplantation. J Cyst Fibros. 2018; 17: 470-474
32. Olejnízková K, Holá V. The comparison of selected virulence factors in Pseudomonas aeruginosa catheter isolates. Epidemiol Mikrobiol Imunol. 2012; 61: 21-8.

33. Lima JLDC, Alves LR, Jacomé PRLA, Bezerra Neto JP, Maciel MAV, Morais MMC. Biofilm production by clinical isolates of Pseudomonas aeruginosa and structural changes in LasR protein of isolates non biofilm-producing. Braz J Infect Dis. 2018; 22: 129-136.

34. da Silva Carvalho T, Rodrigues Perez LR. Impact of biofilm production on polymyxin B susceptibility among Pseudomonas aeruginosa clinical isolates. Infect Control Hosp Epidemiol. 2019; 40: 739-740.

35. Sharma G, Rao S, Bansal A, Dang S, Gupta S, Gabrani R. Pseudomonas aeruginosa biofilm: potential therapeutic targets. Biologicals. 2014; 42: $1-7$.

36. Karatuna O, Yagci A. Analysis of quorum sensing-dependent virulence factor production and its relationship with antimicrobial susceptibility in Pseudomonas aeruginosa respiratory isolates. Clin Microbiol Infect. 2010; 16: 1770-5.

37. Kadhim D, Ali MR. Prevalence study of quorum sensing groups among clinical isolates of Pseudomonas aeruginosa. Int Curr Microbiol App Sci. 2014; 3: 204-215.

38. Pérez-Ibarreche M, Castellano P, Leclercq A, Vignolo G. Control of Listeria monocytogenes biofilms on industrial surfaces by the bacteriocin-producing Lactobacillus sakei CRL1862. FEMS Microbiol Lett. 2016; 363(12). doi: 10.1093/femsle/fnw118

39. Mittal R, Sharma S, Chhibber S, Harjai K. Contribution of quorumsensing systems to virulence of Pseudomonas aeruginosa in an experimental pyelonephritis model. J Microbiol Immunol Infect. 2006; 39: 302-9

40. Vaněrková M, Mališová $B$, Kotásková I, Holá V, Rủžička F, Freiberger T. Biofilm formation, antibiotic susceptibility and RAPD genotypes in Pseudomonas aeruginosa clinical strains isolated from single centre intensive care unit patients. Folia Microbiol. 2017; 62: 531-538. 